\title{
Prototype Pendeteksi Kebocoran Gas LPG Pada Gudang Penyimpanan Gas LPG Berbasis Mikrokontroler
}

\author{
Albar $^{1}$, Ifni Joi ${ }^{2}$, Rozi Helmudyra ${ }^{3}$ \\ ${ }^{123}$ Jurusan Teknik Elektro Politeknik Negeri Padang \\ albar@pnp.ac.id \\ Kampus Politeknik Negeri Padang, Limau Manis Padang
}

\begin{abstract}
The purpose of this research is to make a device that can detect LPG gas leaks in LPG gas storage warehouses. Tools made using Arduino as MQ-2 controllers and sensors to detect LPG gas leaks. The GSM sim800L module functions to send SMS to the operator if it detects LPG gas in the air. The test results show that the sensor detects the presence of LPG gas, the sensor output voltage is 0.95 Vdc. When the sensor does not detect LPG gas, the sensor output is $0.35 \mathrm{Vdc}$. Sim800L requires a Vec voltage of $5 \mathrm{VDC}$ to function. Pin TX has a voltage of 4.2Vdc to send SMS with the condition that there is a danger of gas and $4.4 \mathrm{Vdc}$ when the SMS is not sent.
\end{abstract}

Keywords: Leakage, LPG Gas, Sensor MQ-2, and, GSM Module Sim800L, LCD

Abstrak - Tujuan dilakukannya penelitian ini adalah membuat sebuah alat yang dapat mendeteksi kebocoran gas LPG pada gudang penyimpanan gas LPG. Alat yang dibuat menggunakan arduino sebagai kontroller dan sensor MQ-2 untuk mendeteksi kebocoran gas LPG. Modul GSM sim800L berfungsi mengirimkan sms kepada operator jika mendeteksi gas LPG di udara. Hasil pengujian menunjukkan sensor mendeteksi adanya gas LPG, tegangan output sensor sebesar 0.95 Vdc.Saat sensor tidak mendeteksi gas LPG tengan output sensor sebesar 0,35 Vdc. Sim800L membutuhkan tegangan Vcc sebesar 5 Vdc untuk dapat berfungsi. Pin TX memiliki tegangan 4,2Vdc untuk mengirimkan SMS dengan kondisi ada bahaya gas dan 4,4 Vdc saat SMS tidak terkirim.

Kata kunci: Kebocoran, Gas LPG, Sensor MQ-2, fan, Modul GSM Sim800L, LCD

(C) 2017 Elektron Jurnal Ilmiah

\section{PENDAHULUAN}

Gas LPG banyak dipakai oleh masyarakat sebagai bahan bakar untuk keperluan rumah tangga. Namun dalam beberpa waktu lalu sering terjadi ledakan dan kebakaran yang disebabkan oleh kebocoran gas LPG. Bahan bakar dengan wujud gas ini mempunyai efek negatif, yaitu apa bila menguap di udara bebas akan membentuk lapisan dikarenakan kondensasi. Lapisan yang terbentuk ini bersifat mudah terbakar, sehingga sangat berbahaya apabila terjadi penumpukan di dalam ruangan tertutup dan berpotensi terjadi kebakaran. Contohnya seperti sering tejadi kebakaran dirumahrumah maupun tempat industri yang menggunakan gas LPG tidak jarang menimbulkan kerugian yang sangat besar, baik kerugian materi maupun korban jiwa. Akibat dari kebocoran gas pada suatu ruangan selain menimbulkan kebakaran, kebocoran gas LPG juga akan membuat pencemaran udara. Gas LPG juga dapat membahayakan kesehatan, apabila gas ini terhirup oleh manusia akan menyebabkan susah untuk bernafas, tubuh jadi lemas, akan terasa pusing, mata jadi berkunang-kunag dan kemungkinan terburuk adalah gagal jantung. Untuk mengantisipasi hal yang demikian, maka dibutuhkan sebuah alat yang dapat mendeteksi kebocoran gas LPG sejak dini, sehingga ledakan dan pencemaran udara yang diakibatkan oleh kebocoran gas dapat diketahui lebih awal dan bisa mengurangi terjadinya kebakaran dan pencemaran udara. Oleh karena itu, sesuai dengan permasalahan yang telah dikemukakan, maka dikembangkan sistem untuk mendeteksi kebocoran gas LPG pada gudang penyimpanan gas LPG berbasis mikrokontroller. Tujuan penelitian ini adalah merancang suatu sistem yang dapat mendeteksi kebocoran gas LPG serta memberikan notifikasi melalui pesan sms.

\section{METODE PENELITIAN}

A. Blok Diagram

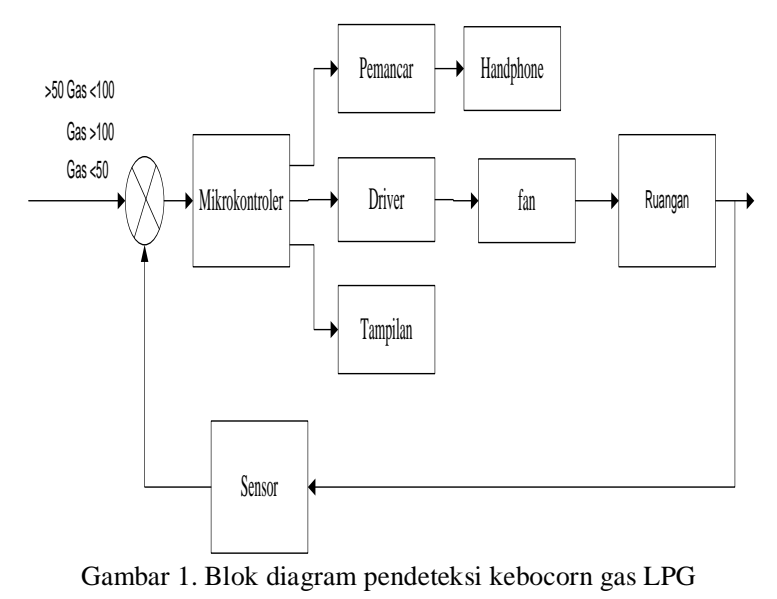


Berdasarkan blok diagram sistem pada Gambar 1 dapat dijelaskan prinsip kerja alat yang dibuat. Prototype alat pendeteksi kebocoran ini berfungsi untuk mendeteksi kebocoran gas, kebocoran gas dapat di deteksi menggunakan sensor MQ-2, jika senssor MQ-2 ini mendeteksi adanya kadar gas di udara/ada gas bocor, maka sensor ini akan meberikan input berupa data kepada LCD, sehingga LCD akan menanmpilakn kondisi udara pada saat sensor mendetaksi gas atau tidak, sensor MQ-2 juga akan memberikan input data pada modul GSM sim800L jika sensor MQ-2 mendeteksi gas LPG dengan nilai ADC besar dari 100 dan menimbulkan potensi bahaya diudara maka modul GSM sim800L akan mengirimkan sms pada penjaga gudang sebagai pemberitahuan ada bahaya kebocoran gas LPG, jika tidak ada gas terdeteksi maka tidak ada pemberitahuan melalui sms dan pada lcd akan tampil "kondisi udara tidak ada gas terdeteksi, dan saat sensor mendeteksi gas dalam jumlah yang sedikit maka pada LCD akan tampil "kondisi udara ada gas terdeteksi". Kipas exchauts fan di fungsikan sebagai alat bantu sirkulasi udara supaya udara di dalam ruangan tetap bersih, selain itu exchauts fan ini juga dapat berfungsi mengeluarkan kandungan gas LPG di udara jiga terjadi kebocoran gas.

\section{B. Perancangan Perangkat Keras (Hardware)}

Mikrokontroler yang digunakan pada alat ini adalah mikrokontroler ATmega 328. Pada mikrokontroler ini terdapat 14 pin digital dan 6 pin analog. Untuk menghubungkan mikrokontroler dengan setiap blok rangkaian digunakan pin header dan konektor. Ini bertujuan agar pengguna dapat mencabut dan memasang sensor dan komponen lainnya ketika ada kerusakan. Input yang digunakan pada alat ini berupa sensor MQ-2,. Sedangkan untuk outputnya berupa LCD 16x2, modul gsm sim800L yang akan mengirimkan sms dan kipas fan exchauts.

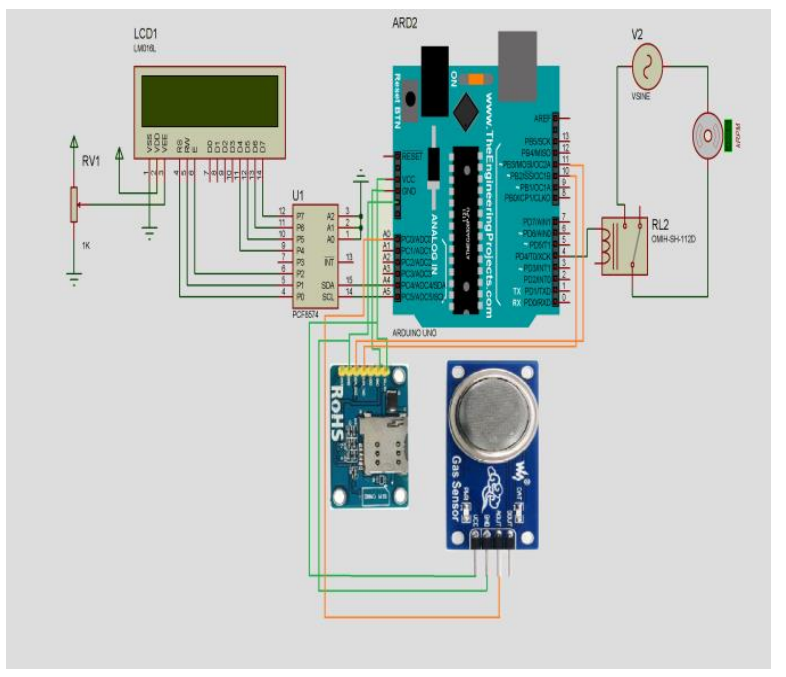

Gambar 2. Rangkaian prototype alat pendeteksi kebocoran gas LPG
Gambar hubungan pin I/O secara keseluruhan pada alat ini dapat dilihat pada gambar dibawah ini. Adapun pin - pin yang digunakan pada mikrokontroler dapat dilihat pada tabel 1 .

Tabel 1. Pin mikrokontroler yang digunakan

\begin{tabular}{ccl}
\hline Bagian & Pin & \multicolumn{1}{c}{ Keterangan } \\
\hline Sensor MQ-2 & A0 & $\begin{array}{l}\text { Pin A0 dihubungkan dengan } \\
\text { pin A0 yang ada pada sensor } \\
\text { MQ-2 }\end{array}$ \\
\hline $\begin{array}{c}\text { Modul GSM } \\
\text { sim800L }\end{array}$ & 10,11 & $\begin{array}{l}\text { Pin 10 dihubungkan ke pin } \\
\text { RXD pada modul sim800L } \\
\text { Pin 11 dihubungkan ke pin } \\
\text { TXD modul sim800L sebagai } \\
\text { pin serial pengirim }\end{array}$ \\
\hline LCD 16x2 & SCL & $\begin{array}{l}\text { Pin SCL dihubungkan ke pin } \\
\text { SCL pada modul I2C dan A4 } \\
\text { SDA terhubung ke pin SDA } \\
\text { modul I2C. }\end{array}$ \\
\hline Relay & SDA & $\begin{array}{l}\text { Pin 3 dihubungkan ke input } \\
\text { relay untuk pengaktifan kipas } \\
\text { fan exchauts }\end{array}$ \\
\hline
\end{tabular}

\section{Perancangan Perangkat Lunak (Software)}

Pada tahap pembuatan software, aplikasi yang digunakan adalah software arduino. Pemrograman merupakan tahapan penginputan instruksi berupa bahasa $\mathrm{C}$ kedalam sistem minimum mikrokontroler. Instruksi ini berisi perintah-perintah yang akan dieksekusi dan menjalankan hardware yang berfungsi sebagai pengeksekusi dan menjalankan hardware. Agar perancangan software mudah dilakukan dengan cepat maka terlebih dahulu membuat sebuah flow chart untuk menggambarkan jalannya sebuah program secara keseluruhan. Setelah perancangan flow chart selanjutnya adalah pembuatan program dengan menggunakan software arduino IDE. Flowchart dari alat pendeteksi kebocoran LPG dapat dilihat pada gambar 3 .

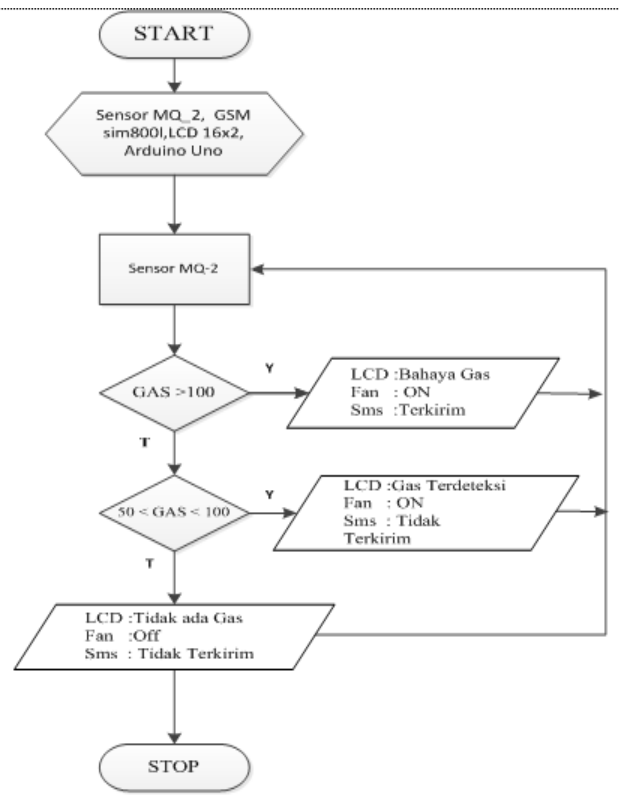

Gambar 3. Flowchart 


\section{HASIL DAN PEMBAHASAN}

Setelah pembuatan alat selesai dilakukan, maka tahap selanjutnya yaitu pengujian alat. Pada tahap pengujian alat ini bertujuan agar mengetahui apakah alat bekerja sesuai dengan harapan. Gambar 4 adalah prototype alat yang telah dibuat.

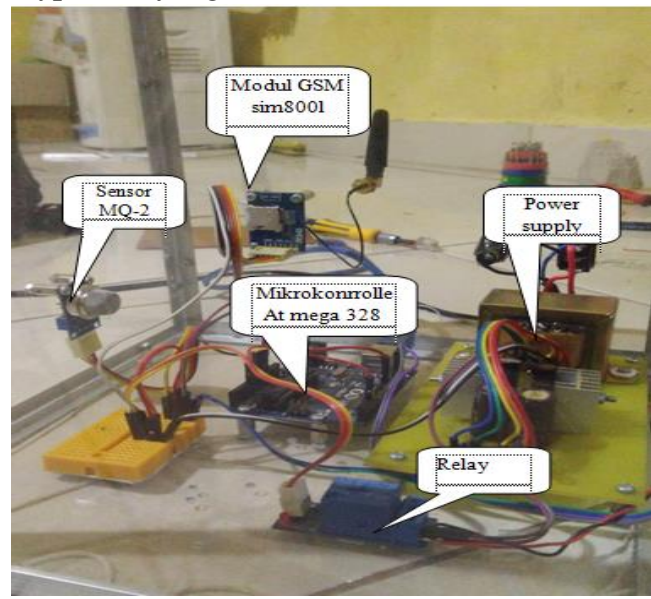

Gambar 4. Prototype Alat pendeteksi kebocoran LPG

pengujian dan analisa pada prototype alat pendeteksi kebocoran gas LPG adalah

1. Sensor MQ-2

2. Relay

3. Modul SIM 800L

\section{A. Pengujian dan Analisa Rangkaian Sensor MQ-2}

Tujuan dari pengujian sensor MQ-2 ini, untuk mengetahui tegangan outpurt dari sensor gas MQ-2 pada saat sensor MQ-2 mendeteksi gas LPG. Data hasil pengukuran gas pada sensor MQ-2 dapat dilihat pada tabel 2 .

Tabel 2. Data hasil pengukuran gas pada sensor MQ-2

\begin{tabular}{|c|c|c|c|c|}
\hline Percobaan & Waktu & $\begin{array}{l}\text { Data ADC } \\
\text { Sensor } \\
\text { MQ-2 }\end{array}$ & $\begin{array}{l}\text { Vout } \\
\text { Sensor } \\
\text { MQ-2 }\end{array}$ & $\begin{array}{l}\text { Kondisi } \\
\text { Udara }\end{array}$ \\
\hline \multirow{2}{*}{1} & \multirow{2}{*}{5 menit } & 28 & 0,1 & \multirow{5}{*}{$\begin{array}{c}\text { Tidak } \\
\text { Ada Gas } \\
\text { terdeteksi }\end{array}$} \\
\hline & & 33 & 0,3 & \\
\hline \multirow{2}{*}{2} & \multirow{2}{*}{5 menit } & 35 & 0,5 & \\
\hline & & 34 & 0,5 & \\
\hline $\begin{array}{l}\text { Rata-rata } \\
\text { Vout sensor } \\
\text { MQ-2 }\end{array}$ & - & - & 0,35 & \\
\hline \multirow{2}{*}{3} & \multirow{2}{*}{5 menit } & 58 & 0,9 & \multirow{5}{*}{$\begin{array}{c}\text { Gas } \\
\text { terdeteksi }\end{array}$} \\
\hline & & 55 & 0,8 & \\
\hline \multirow{2}{*}{4} & \multirow{2}{*}{5 menit } & 60 & 0,9 & \\
\hline & & 87 & 1,2 & \\
\hline $\begin{array}{l}\text { Rata-rata } \\
\text { Vout sensor } \\
\text { MQ-2 }\end{array}$ & & - & 0,95 & \\
\hline \multirow{2}{*}{5} & \multirow{2}{*}{5 menit } & 109 & 1,8 & \multirow{4}{*}{$\begin{array}{c}\text { Bahaya } \\
\text { Gas }\end{array}$} \\
\hline & & 104 & 1,7 & \\
\hline \multirow{2}{*}{6} & \multirow{2}{*}{5 menit } & 153 & 2,1 & \\
\hline & & 217 & 2,4 & \\
\hline
\end{tabular}

Rata-rata

Vout sensor

MQ-2

Sensor mendeteksi adanya gas LPG, pada serial monitor akan terlihat data ADC. Semakin besar volume gas dalam ruangan maka data yang ditampilkan semakin tinggi nilainya dan tegangan yang terukur pada sensor akan semakin tinggi . Ketika sensor MQ-2 mendeteksi gas, dapat kita lihat data ADC yang ditampilkan akan berbanding lurus dengan tegangan sensor yang dihasilkan.

\section{B. Pengujian dan Analisa Rangkaian Relay}

Pengukuran pada relay ini untuk melihat kondisi transistor yang berperan sebagai saklar pada relay saat transistor di titik saturasi yang dipicu oleh Mikrokontroler. Berdasarkan hasil dari pengukuran pada titik pengukuran sesuai dengan gambar 4 dapat dilihat pada tabel 3 adalah sebagai berikut. Rangkaian relay dirancang dengan memanfaatkan transistor sebagai saklar. Apabila transistor diberi tegangan 5 Vdc dengan logika high, maka akan membuat transistor bekerja. Transistor akan bekerja apabila tegangan pada VBE telah mencapai tegangan kerja transistor 0.83 Volt.

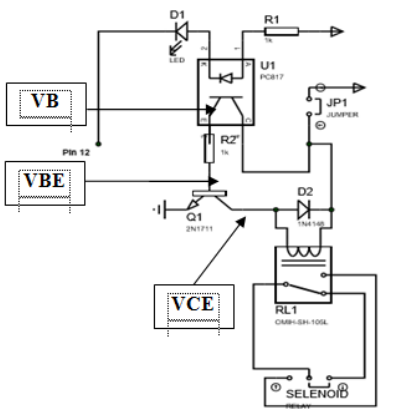

Gambar 4. Titik Pengukuran Relay

Tabel 3. Hasil pengukuran rangkaian relay

\begin{tabular}{ccc}
\hline \multirow{2}{*}{ Relay } & $\begin{array}{c}\text { Kondisi Input } \\
\text { Low }\end{array}$ & $\begin{array}{c}\text { Kondisi Input } \\
\text { High }\end{array}$ \\
\cline { 2 - 3 } & Tegangan NC & Tegangan NC \\
\hline Relay (TP1) & $0 \mathrm{~V}_{\mathrm{DC}}$ & $11,6 \mathrm{~V}_{\mathrm{DC}}$ \\
\hline
\end{tabular}

Ketika transistor bekerja maka anak kontak relay akan mengaktifkan kipas fan exchaut. Pada transistor bekerja sebagai saklar yang ditandai dengan tegangan yang dihasilkan pada VCE, jika tegangan VCE = Vcc maka tegangan tersebut berada dalam keadaan Cut Off. Sedangkan jika VCE < VCC. Maka tegangan tersebut berada dalam saturasi.

\section{Pengujian dan Analisa Modul GSM sim800L}

Pengujian pada SIM800L berfungsi untuk mengetahui nilai tegangan dalam keadaan mengirim 
SMS. Gambar 5 merupakan titik pengujian modul SIM800L

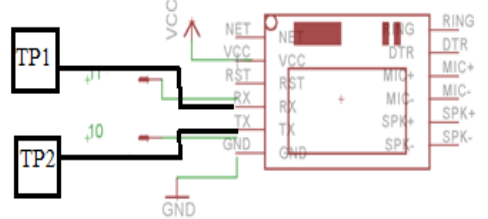

Gambar 5 Titik pengujian modul SIM800L

Hasil Hasil Pengukuran modul GSM sim800L dapat dilihat pada tabel 4.

Tabel 4. Hasil Pengukuran modul GSM sim800L

\begin{tabular}{|c|c|c|c|c|c|}
\hline \multirow{2}{*}{$\begin{array}{l}\text { Vin } \\
(\mathrm{Vdc})\end{array}$} & \multirow{2}{*}{$\begin{array}{l}\text { SIM } \\
8001\end{array}$} & \multirow{2}{*}{$\begin{array}{c}\text { SMS } \\
\text { yang di } \\
\text { kirimkan }\end{array}$} & \multicolumn{2}{|c|}{$\begin{array}{c}\text { Titik pengukuran } \\
\text { SIM8001 }\end{array}$} & \multirow{2}{*}{$\begin{array}{c}\text { Data } \\
\text { ADC } \\
\text { sensor } \\
\text { MQ-2 }\end{array}$} \\
\hline & & & $\begin{array}{c}\text { TP1 } \\
(\mathrm{Vdc})\end{array}$ & $\begin{array}{c}\text { TP2 } \\
\text { (Vdc) }\end{array}$ & \\
\hline 5 & $\begin{array}{c}\text { Tidak } \\
\text { mengirim } \\
\text { sms }\end{array}$ & & 4,6 & 4,4 & $<50$ \\
\hline 5 & $\begin{array}{c}\text { Tidak } \\
\text { mengirim } \\
\text { sms }\end{array}$ & & 4,6 & 4,4 & $\begin{array}{l}<100 X \\
>50\end{array}$ \\
\hline 5 & $\begin{array}{l}\text { Mengirim } \\
\text { sms }\end{array}$ & $\begin{array}{c}\text { Ada } \\
\text { bahaya } \\
\text { gas }\end{array}$ & 4,2 & 4,2 & $>100$ \\
\hline
\end{tabular}

Dari tabel 4 didapatkan analisa bahwa sim800L membutuhkan tegangan Vcc sebesar 5 VDC untuk dapat berfungsi. Pin TX memiliki tegangan 4,2V untuk mengirimkan SMS dengan kondisi ada bahaya gas dan 4,4 VDC saat SMS tidak terkirim. Gambar 6 merupakan pesan sms yang diterima jika ada bahaya gas.

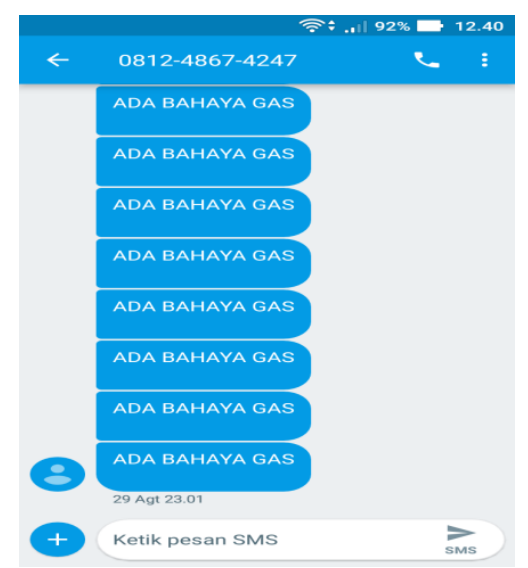

Gambar 6. Tampilan sms jika ada bahaya gas

\section{IV.KESIMPULAN}

1. Ketika Sensor mendeteksi adanya gas LPG, tegangan output sensor sebesar 0.95 VDC. Saat kondisi udara dalam keadaan bahan gas LPG tegangan output sensor sebesar 2,0 VDC. Saat sensor tidak mendeteksi gas LPG tengan output sensor sebesar 0,35 VDC.

2. LCD pada alat ini berfungsi untuk menampilkan kondisi udara pada ruangan, jika data ADC pembacaan sensor MQ-2 kurang dari 50 LCD menampilakn kondisi udara tidak terdeteksi gas LPG, data ADC besar dari 50 kecil dari 100 menampilkan kondisi udara gas terdeteksi pada LCD, data ADC besar dari 100 akan LCD akan menampilkan kondisi udara bahaya gas.

3. Modul GSM sim800L berfungsi sebagai perangkat interface untuk menberi notifikasi berupa pesan sms, sms akan terkirim jika kondisi udara bahaya gas.

\section{REFERENSI}

[1] Drs. Suhaedi, MT. 2012. Perancangan Sensor Gas HS133 Sebagai Pendeteksi Kebocoran Pada Gas LPG. Jurnal Saint Terapan. Vol 4, No.1 2012.Hal 1-5

[2] Lavanna Indanus Ramadhan, Dahnial Syauqy, Barlian Henryranu Prasetio. 2017. istem Pendeteksi Kebocoran Gas LPG Menggunakan Metode Fuzzy yang Diimplementasikan dengan Real Time Operating System (RTOS). Jurnal Pengembangan Teknologi Informasi dan Ilmu Komputer. Vol. 1, No. 11, November 2017, hlm. 1206-1213.

[3] Christian Joko, Komar Nurul. Prototipe Sistem Pendeteksi Kebocoran Gas LPG Menggunakan Sensor Gas MQ2, Board Arduino Duemilanove, B, dan Arduino GSM Shield pada PT. Alfa Retailindo (Carrefour Pasar Minggu). Jurnal TICOM, Vol. 2 No. 1, September 2013.

[4] Rachmad Hidayatullah,, Husnibes Muchtar. 2015. Robot Pendeteksi Kebocoran Gas Menggunakan Mikrokontroller Atmega 328 Dan Sensor Gas MQ6. êLEKTUM, Vol.11, No.2, November 2015. Hal 36-46

[5] P. Jyothi ; G. Harish. 2016. Design and implementation of real time vehicle monitoring, tracking and controlling system. 2016 IEEE International Conference on Communication and Electronics Systems (ICCES). India

[6] Prashant A. Shinde ; Y.B. Mane. 2015. Advanced vehicle monitoring and tracking system based on Raspberry Pi. 2015 IEEE 9th International Conference on Intelligent Systems and Control (ISCO). India

[7] Ashish Shrivastava, Ratnesh Prabhaker, Rajeev Kumar and Rahul Verma. 2013. Gsm Based Gas Leakage Detection System. International Journal of Technical Research and Applications Volume 1, Issue 2 (may-june 2013), PP. 42-45 